\title{
Combination therapy adding tadalafil to existing ambrisentan in patients with pulmonary arterial hypertension
}

\author{
Akihiro Hirashiki, Takahisa Kondo and Toyoaki Murohara \\ Hypertension Research (2014) 37, 488-489; doi:10.1038/hr.2014.37; published online 20 March 2014
}

\section{CLINICAL PRACTICE AND PRACTICE GUIDELINES}

$\mathrm{T}$ the current era of multiple therapies for 1 pulmonary arterial hypertension (PAH), the use of combination therapy is becoming common. The REVEAL registry demonstrated that nearly $50 \%$ of patients with $\mathrm{PAH}$ received $>1$ treatment. ${ }^{1}$ Although there is currently no evidence, this approach may be favored over monotherapy in PAH patients. In fact, the 2008 World Symposium on pulmonary hypertension published a treatment algorithm in which combining drugs in the three treatment classes received a grade $\mathrm{B}$ recommendation for patients who remain symptomatic with initial therapy. ${ }^{2}$

Studies are ongoing to guide clinicians as to how to use these therapies, including alone or in combination. Combination therapy will have an important role as a main therapeutic option for patients with PAH.

\section{ENDOTHELIN RECEPTOR ANTAGONISTS AND PHOSPHODIESTERASE TYPE 5 INHIBITORS}

Endothelin (ET-1) is a potent vasoconstrictor that has a key role in the pathophysiology of PAH. ET-1 binds to two distinct receptor isoforms in pulmonary vascular smooth muscle cells: endothelin A and B receptors. ${ }^{3}$ ET-1 receptor antagonists (ERAs) approved for the treatment of $\mathrm{PAH}$ include the nonselective $\mathrm{ET}_{\mathrm{A}} / \mathrm{ET}_{\mathrm{B}}$ receptor antagonist,

A Hirashiki and $\mathrm{T}$ Kondo are at Department of Advanced Medicine in Cardiopulmonary Disease, Nagoya University Graduate School of Medicine, Nagoya, Japan; T Murohara is at Department of Cardiology, Nagoya University Graduate School of Medicine, Nagoya, Japan

E-mail: hirasiki@med.nagoya-u.ac.jp bosentan and the selective $\mathrm{ET}_{\mathrm{A}}$ receptor antagonist, ambrisentan. Ambrisentan does not reduce ET-1-mediated nitric oxide production or $\mathrm{ET}_{\mathrm{B}}$ receptor-mediated ET-1 clearance. ${ }^{4}$ In addition, ambrisentan has been demonstrated to be associated with fewer adverse effects in the liver and a reduced incidence of drug interactions. ${ }^{5} \mathrm{PAH}$ patients exhibit an increased expression of phosphodiesterase type 5 (PDE-5), leading to reduced cyclic guanosine monophosphate. Therefore, PDE-5 inhibitors constitute a potential therapeutic option. Both sildenafil and tadalafil as PDE-5 inhibitors are approved for the clinical treatment of PAH. However, the use of tadalafil may be preferable due to the medication's once daily dosing scheme.

\section{CURRENT COMBINATION THERAPY}

Many potential therapeutic options are now available for $\mathrm{PAH}$ patients. Interest has emerged in using therapies in various combinations. In particular, combining oral PAH therapies is a very attractive approach compared with the more complex intravenous administration of epoprostenol. Several open-label trials are currently investigating the combination of ERAs and PDE-5 inhibitors. The tadalafil in the treatment of $\mathrm{PAH}$ (PHIRST) trial, a randomized, double-blind, placebo-controlled trial of the efficacy and safety of tadalafil, enrolled 405 patients. ${ }^{6}$ In that trial, $53 \%$ of the patients received bosentan as background therapy. The results demonstrated that the 6-min walking distance significantly increased in patients on background bosentan and treatmentnaive patients compared with that observed in patients receiving a placebo, although the benefits were smaller in the patients treated with bosentan. The COMPASS- 1 trial was a prospective study of the pharmacodynamic effects of sildenafil in patients receiving bosentan therapy. In that trial, the patients receiving stable bosentan treatment for 3 months with a 25-mg dose of sildenafil exhibited significantly decreased pulmonary vascular resistance. ${ }^{7}$ Several randomized controlled trials of combination therapy with ERAs and PDE-5 inhibitors are ongoing. One such trial, the COMPASS-2 trial, is currently examining the long-term effects of the addition of bosentan to sildenafil on morbidity and mortality.

Demonstrating the benefits of combination approaches is challenging. Zhuang et al. ${ }^{8}$ investigated whether adding tadalafil to existing ambrisentan is safe and effective in patients with $\mathrm{PAH}$ and reported that the tadalafil group showed a significantly improved exercise capacity as assessed by the 6-min walking distance at week 16 compared with the placebo group $(P<0.05)$. In addition, $8.3 \%$ of the patients receiving tadalafil as an add-on therapy and $23.4 \%$ of the patients treated with a placebo exhibited clinical worsening (CW) $(P<0.05)$. There were no significant differences in adverse events or changes in hemodynamic parameters between the placebo and tadalafil groups. These results suggest that adding tadalafil to existing ambrisentan treatment is attractive with regard to both safety and compliance in patients with $\mathrm{PAH}$.

\section{New combination therapy}

Although some clinical trials have shown beneficial effects on exercise capacity, pulmonary hemodynamics or time to $\mathrm{CW}$, it is very difficult to distinguish whether the 
improvements are the result of the combined effects of the new agent with the background therapy or merely represent a response to the new medicine. The ongoing AMBITION (NCT01178073) and ATPAHSS (NCT01042158) studies should shed light on this question by directly comparing the efficacy of the first-line upfront combination of tadalafil and ambrisentan versus the use of each drug alone in patients with PAH. In addition, the various published meta-analyses examining the effects of monotherapy versus combination therapy for PAH have provided inconsistent results. The true value of combination therapy remains controversial to date, despite its broad acceptance and application in daily clinical practice. ${ }^{9,10}$

\section{CONFLICT OF INTEREST}

The authors declare no conflict of interest.
1 McGoon MD, Miller DP. REVEAL: a contemporary US pulmonary arterial hypertension registry. Eur Respir Rev 2012; 21: 8-18.

2 Barst RJ, Gibbs JS, Ghofrani HA, Hoeper MM, McLaughlin VV, Rubin LJ, Sitbon O, Tapson VF, Galiè N. Updated evidence-based treatment algorithm in pulmonary arterial hypertension. J Am Coll Cardiol 2009; 54(1 Suppl), S78-S84.

3 Channick RN, Simonneau G, Sitbon O, Robbins IM, Frost A, Tapson VF, Badesch DB, Roux S, Rainisio M, Bodin F, Rubin LJ. Effects of the dual endothelinreceptor antagonist bosentan in patients with pulmonary hypertension: a randomised placebo-controlled study. Lancet 2001; 358: 1119-1123.

4 Hirata Y, Emori T, Eguchi S, Kanno K, Imai T, Ohta K, Marumo F. Endothelin receptor subtype B mediates synthesis of nitric oxide by cultured bovine endothelial cells. J Clin Invest 1993; 91: 1367-1373.

5 Galie N, Olschewski H, Oudiz RJ, Torres F, Frost A, Ghofrani HA, Badesch DB, McGoon MD, McLaughlin VV, Roecker EB, Gerber MJ, Dufton C, Wiens BL, Rubin LJ. Ambrisentan in Pulmonary Arterial Hypertension, Randomized, Double-Blind, PlaceboControlled, Multicenter, Efficacy Studies (ARIES) Group. Ambrisentan for the treatment of pulmonary arterial hypertension: results of the ambrisentan in pulmonary arterial hypertension, randomized, doubleblind, placebo-controlled, multicenter, efficacy (ARIES) study 1 and 2. Circulation 2008; 117: 3010-3019.

6 Galie N, Brundage BH, Ghofrani HA, Oudiz RJ, Simonneau G, Safdar Z, Shapiro S, White RJ, Chan M, Beardsworth A, Frumkin L, Barst RJ. Pulmonary Arterial Hypertension and Response to Tadalafil (PHIRST) Study Group. Tadalafil therapy for pulmonary arterial hypertension. Circulation 2009; 119: 2894-2903.

7 Gruenig E, Michelakis E, Vachiery JL, Vizza CD, Meyer FJ, Doelberg M, Bach D, Dingemanse J, Galiè N. Acute hemodynamic effects of single-dose sildenafil when added to established bosentan therapy in patients with pulmonary arterial hypertension: results of the COMPASS-1 study. J Clin Pharmacol 2009; 49: 1343-1352.

8 Zhuang $\mathrm{Y}$, Jiang $\mathrm{B}$, Gao H, Zhao W. Randomized study of adding tadalafil to existing ambrisentan in pulmonary arterial hypertension. Hypertens Res 2014; 37: 507-512.

9 Fox BD, Shimony A, Langleben D. Meta-analysis of monotherapy versus combination therapy for pulmonary arterial hypertension. Am J Cardiol 2011; 108: 1177-1182.

10 Bai Y, Sun L, Hu S, Wei Y. Combination therapy in pulmonary arterial hypertension: a meta-analysis. Cardiology 2011; 120: 157-165. 